\title{
APPLYING NUMERICAL METHOD IN THE STRENGTH CALCULATION OF HIGH PRESSURE STEAMLINE
}

\author{
Dragan Čukanović* \\ University of Priština, Faculty of Technical Sciences, Kosovska Mitrovica, Serbia \\ Dr Miroslav Živković \\ University of Kragujevac, Faculty of Engineering, Kragujevac, Serbia \\ Mr Aleksandar Jakovljević \\ Electric Power Industry of Serbia \\ Dr Slobodan Savić \\ University of Kragujevac, Faculty of Engineering, Kragujevac, Serbia
}

This paper analyses the distribution of stress through steam line of medium superheated steam with the special emphasis on the critical location, the bend, in order to estimate the remaining lifecycle of a steam line. Moreover it presents the theoretical basis of the beam superelement with $2 D$ cross-section segment which was used for analysis in PAK software. The obtained results of stress analysis and estimated reliability of the construction after 200.000 hours of exploitation are shown.

Keywords: High pressure steam line, Beam superelement, PAK-software, Stress, Lifecycle of construction

\section{INTRODUCTION}

High pressure steamlines represent critical components of thermal power facilities which significantly affect the reliability and availability of facilities as well as the safety and security of personnel. Therefore, in their exploitation special attention should be given to monitoring and reviewing their state, in order to estimate the remaining lifecycle. High pressure steamlines operate in the conditions of high temperature and pressure on one side and of low-cycle fatigue at the starting and stopping point of the facility on the other side. Depending of constructions there are several methods for analyzing the reliability of a complex system such as the Generic Parts Count Analysis, the Failure Mode Effect and Criticality Analysis, the Event Tree Analysis, the Fault Tree Analysis as given in [08]. Applying software package based on the theory of finite elements enables modeling of constructions in order to analyze stress and strain and to estimate reliability of construction during the remaining lifecycle [03]. This paper shows theoretical basis of beam superelement with $2 \mathrm{D}$ cross section segment that the strength calculations are based on. Thereafter the calculation of high pressure steamline in PipePak software [01] is presented in order to obtain the results of forces and moments at the critical location of steamline. Based on that data detailed stress analysis at the critical location has been done using PAK$S$ software [06] for calculation and FEMAP software [04] in the pre- and post-processing phase. The obtained results have led to the relevant conclusions on the strength and remaining lifecycle of construction.

\section{BEAM FINITE ELEMENT OF DEFORMABLE CROSS-SECTION AND GENERAL GEOMETRY}

The basic assumption is that for the part of the construction which is to be replaced by one such element, we can notice one direction (longitudinal axis) along which the structure is invariable in geometric and material terms (Figure 1a). Planes which can be placed orthogonally to the longitudinal axis are the cross-sectional planes. In the cross-sectional plane, we can determine the shape and material structure of the crosssection, which can be arbitrary (Figure 1b). At the reference beam axis whose direction coincides with the longitudinal axis the main beam nodes are being defined. The basic assumption is that each of such beam elements, which could 
be of a very complex structure, can be modeled by isoparametric subelements (Figure 1c). Since the beam element consists of sub-elements (isoparametric 3D, a shell and a beam) it can be

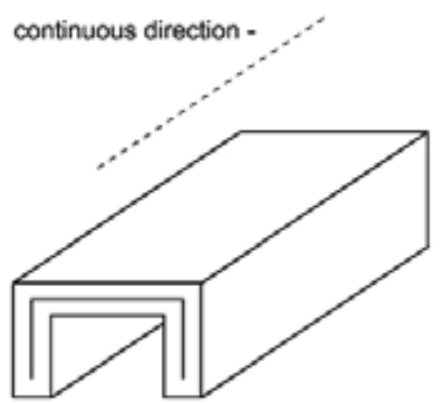

(a)

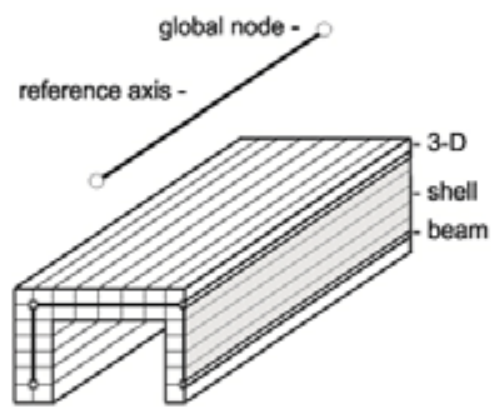

(c) considered as a superelement. The number and type of subelements depend on the geometric and material properties of the representative cross-sections [07].

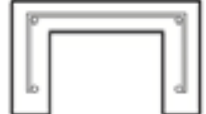

(b)

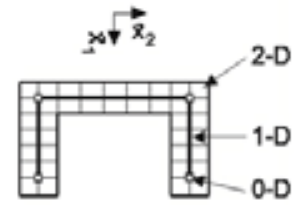

(d)

Figure 1: Modeling of a complex construction with beam superelement (a) longitudinal axis, (b) cross-section, (c) subelements of beam superelement, (d) segments in the representative cross-section

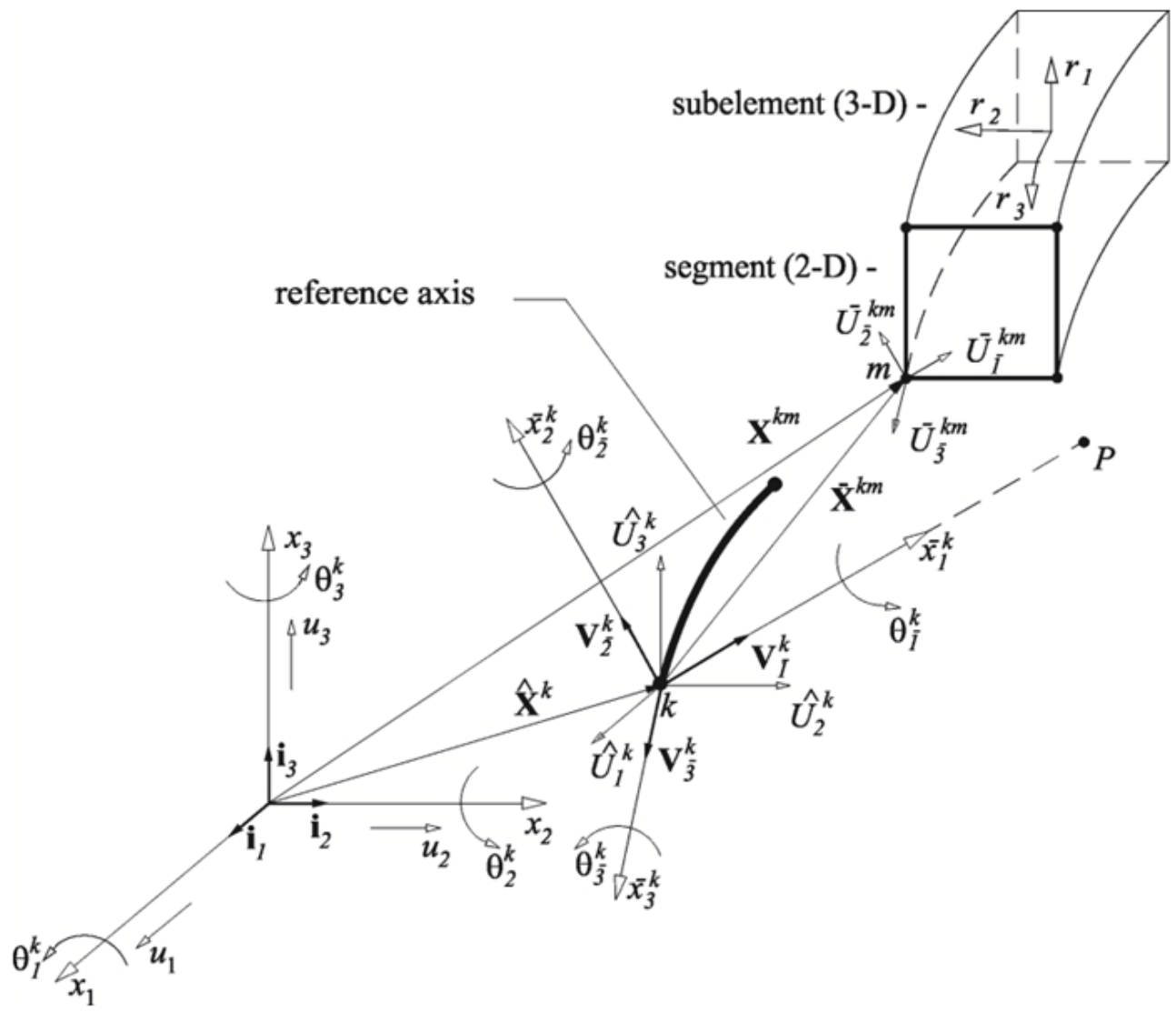

Figure 2: The geometry of the beam superelement with $2 D$ cross-section seg- 
The representative cross-sections are beam cross-sections in the main nodes of beam element. In the representative cross-section we can see the cross-sections of each subelement (Figure 1d). Cross-section of 3D subelement corresponds to the 2D (or surface) segment, crosssection of shell corresponds to 1D (or line) segment, cross-section of beam corresponds to OD (or point ) segment. Segments are described by the nodes which are in the plane of the representative cross-sections and their position is specified in relation to the coordinate systems connected to the main beam nodes. One subelement in each representative cross-section of beam element has the appropriate segment that defines it. If all relative motions are constrained, stiffness matrix and force vector of subelements are directly added to the global stiffness matrix of the construction and to the global load vector. In the case of joint relative displacements of superelements the stiffness matrix and the force vector are formed at the level of elements group. The total number of equations for the group is obtained as the sum of the number of equations corresponding to the main beam nodes and nodes of all segments of the cross-sections in the group.

The equilibrium equation for the group is

$$
\left[\begin{array}{cc}
\overline{\mathbf{K}} & \hat{\mathbf{K}} \\
\hat{\mathbf{K}}^{\mathrm{T}} & \hat{\mathbf{K}}
\end{array}\right]\left[\begin{array}{c}
\overline{\mathbf{U}} \\
\hat{\mathbf{U}}
\end{array}\right\}=\left\{\begin{array}{c}
\overline{\mathbf{F}} \\
\hat{\mathbf{F}}
\end{array}\right\}
$$

where $\quad \overline{\mathbf{U}}$ and $\quad \hat{\mathbf{U}}$ are vectors of relative and global nodes displacement of segments corresponding to appropriate stiffness matrix $\overline{\mathbf{K}}, \hat{\mathbf{K}}$ and force vectors $\overline{\mathbf{F}}, \hat{\mathbf{F}}$. $\hat{\mathbf{K}}$ is stiffness matrix which connects global and relative values of displacement and forces.

\section{BEAM SUPERELEMENT WITH 2D SEGMENT IN THE CROSS-SECTION}

The geometry of beam superelement with coordinate systems and position vector, 3D subelement and 2D segment in the cross-section are shown in the Figure 2.

\section{LINEAR-ELASTIC STRESS ANALYSIS}

The primary aim of modeling steam line in $\mathrm{Pi}$ pePak software was to obtain the values of forces and moments at the critical bend (Figure3) for further detailed stress analysis using PAK-S software for calculation as well as FEMAP in the phases of pre- and post-processing.

Table 1 shows the dimensions of the pipe bend based on which the model has been formed using FEMAP software.

Table 1. Dimensions of pipe bend

\begin{tabular}{|c|c|c|c|c|c|}
\hline \multicolumn{2}{|c|}{ Diametre } & \multicolumn{4}{c|}{ Wall thickness } \\
\hline $\mathrm{d}_{1}$ & $\mathrm{~d}_{1}$ & Tensed zone & Neutral zone 1 & Pressed zone & Neutral zone 2 \\
\hline $\mathrm{mm}$ & $\mathrm{mm}$ & $\mathrm{mm}$ & $\mathrm{mm}$ & $\mathrm{mm}$ & $\mathrm{mm}$ \\
\hline 422.0 & 420.5 & 12.2 & 13.0 & 14.9 & 13.0 \\
\hline
\end{tabular}

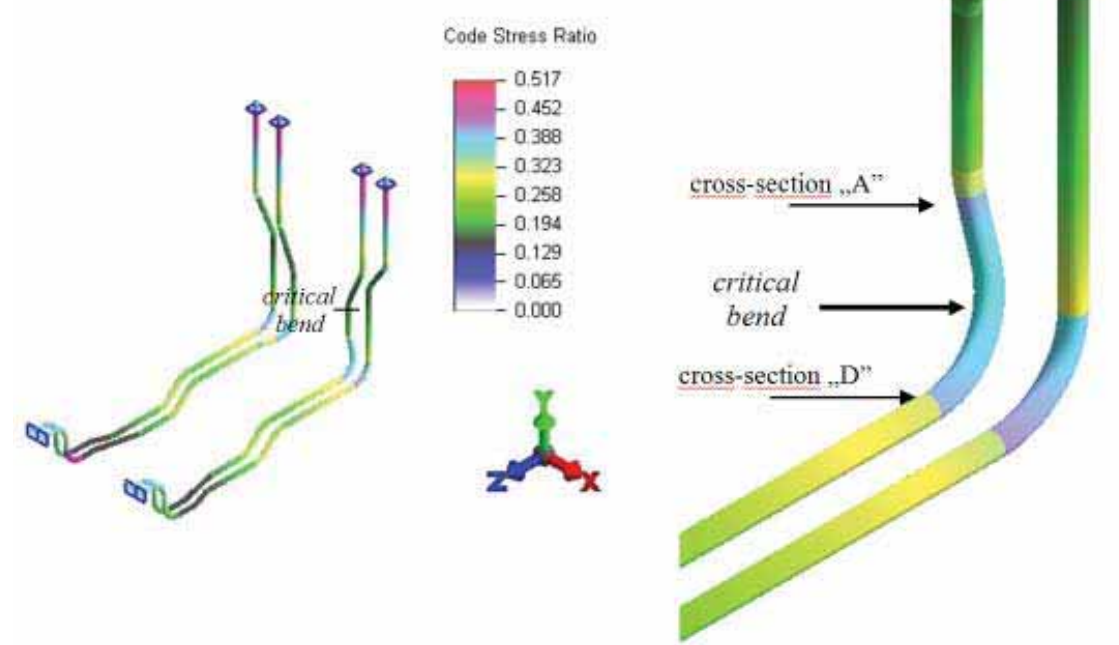

Figure 3: The forces and moments at the critical bend 
Finite element (FE) model of bend is created by modelling separately the cross-section (Figure 4 ) and the bend (Figure 6) and then combining their * dat file. The detailed description of the procedure of obtaining the FE model of bend will be explained in the next few steps. Based on the data in the Table 1 the geometry of cross-section has been created. In Table 1 we can see that diameters in the tensed and pressed zone are different so that the cross-section is created as two ellipses whose centers are moved 1,35 $\mathrm{mm}$ along the $\mathrm{y}$-direction. The structure of the steamline pipe bend is discretized by $2 \mathrm{D}$ finite elements. FE model of pipe bend is discretized at 3456 elements. 12 segments along the pipe bend axis (at each $7.5^{\circ}$ ), 48 segments along the

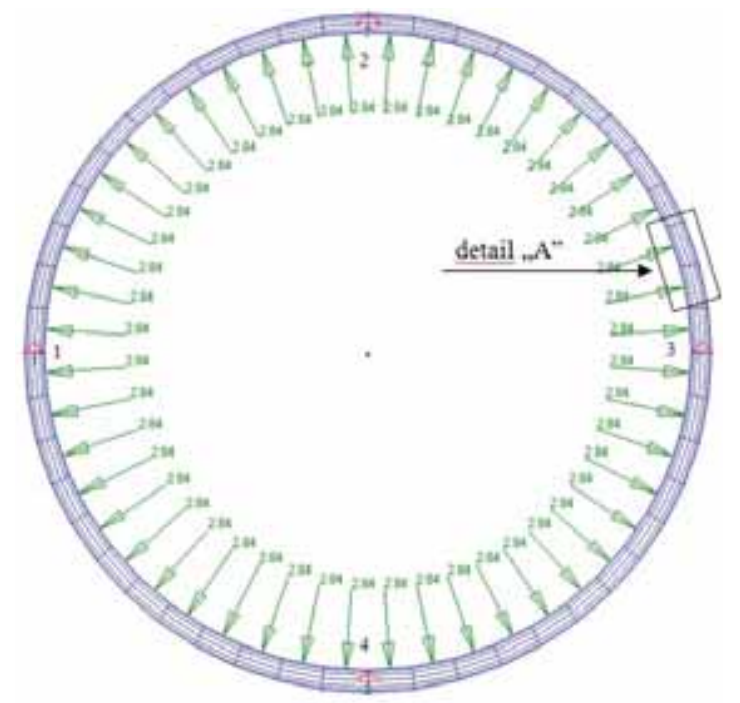

Figure 4: Finite element mesh

Figure 6 shows the FE model of pipe bend discretized by beam finite elements.

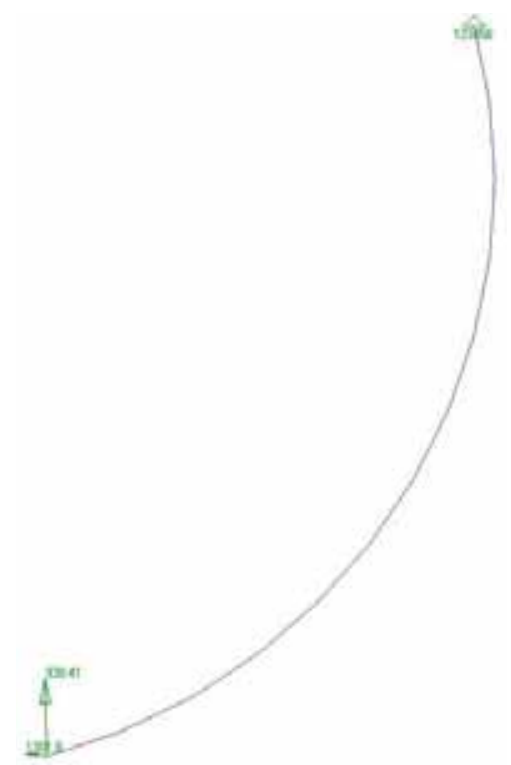

Figure 6: Finite element mesh circumference of cross-section (at each $7.5^{\circ}$ ) and 6 layers of elements along wall thickness (Figure 4) have been created. Segments along the longitudinal and tangential direction are equal while the distribution along the thickness of the cross-section has been made in such a way that the surface elements are thinner than those in the middle section in order to be able to more closely monitor changes in stress values on the surface elements, that is, exactly where this change is the most intense. A detail of the finite element mesh along the wall thickness is shown in Figure 5. Translation in $\mathrm{x}$-direction of nodes 1 and 3 and translation in $y$-direction of nodes 2 and 4 are constrained. Pipe bend is under the pressure of $2.84 \mathrm{MPa}$.

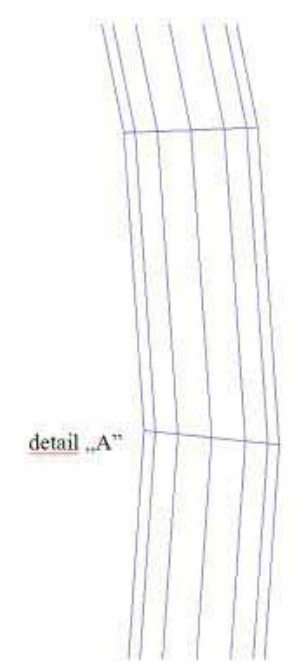

Figure 5: Elements through the thickness of the wall

The set values for loads, forces and moments were obtained as output result of the previously mentioned analysis in PipePak software (Table 2).

Table 2: Forces and moments

\begin{tabular}{|c|c|c|}
\hline \multirow{2}{*}{ Critical bend } & \multicolumn{2}{|c|}{ Hot state } \\
\cline { 2 - 3 } & cross-section A & cross-section D \\
\hline \hline Fx $(\mathrm{N})$ & 355 & -355 \\
\hline \hline Fy $(\mathrm{N})$ & -725 & 5759 \\
\hline $\mathrm{Fz}(\mathrm{N})$ & 10.694 & -10.694 \\
\hline \hline $\mathrm{Mx}(\mathrm{Nm})$ & 58.466 & -68.576 \\
\hline $\mathrm{My}(\mathrm{Nm})$ & -4882 & 559 \\
\hline $\mathrm{Mz}(\mathrm{Nm})$ & -835 & 211 \\
\hline
\end{tabular}

Upon the modeling of the cross-section and pipe bend, two files were obtained. By combining and setting appropriate parameters of the files we receive one input file, ready for analysis in the PAK- 
$\mathrm{S}$ software. The analysis performed in PAK-S is based on the beam superelement the theoretical

basis of which is already given. The results of certain stresses are shown in Figures 7 and 8.
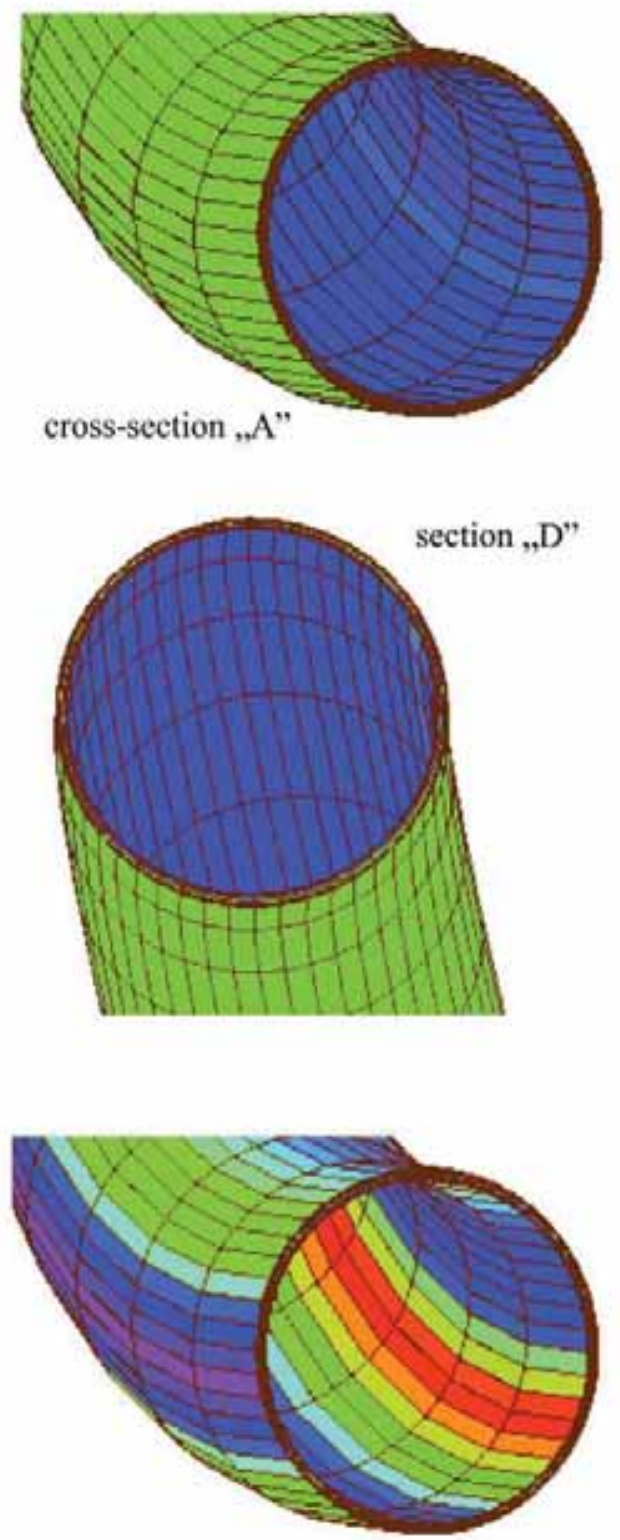

cross-section "A"

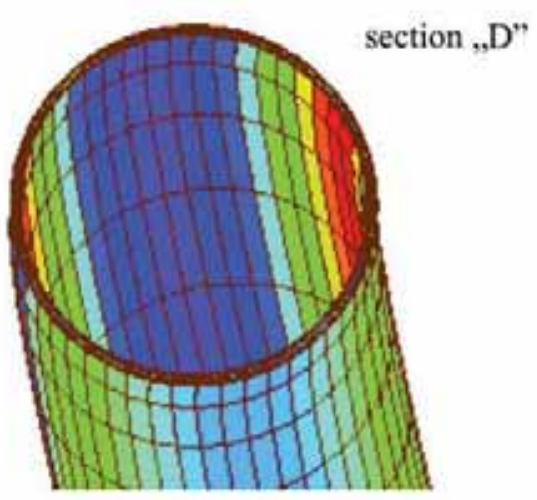

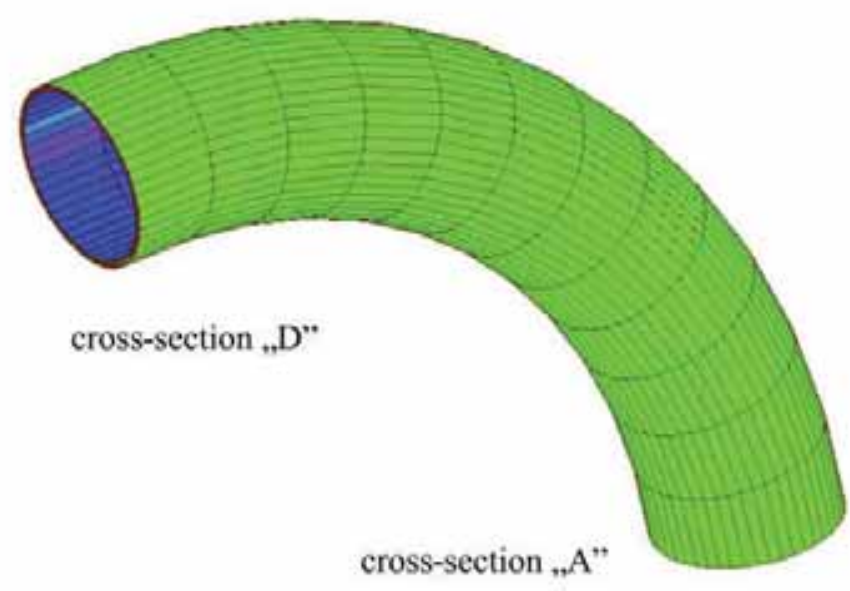

RADIAL STRESS

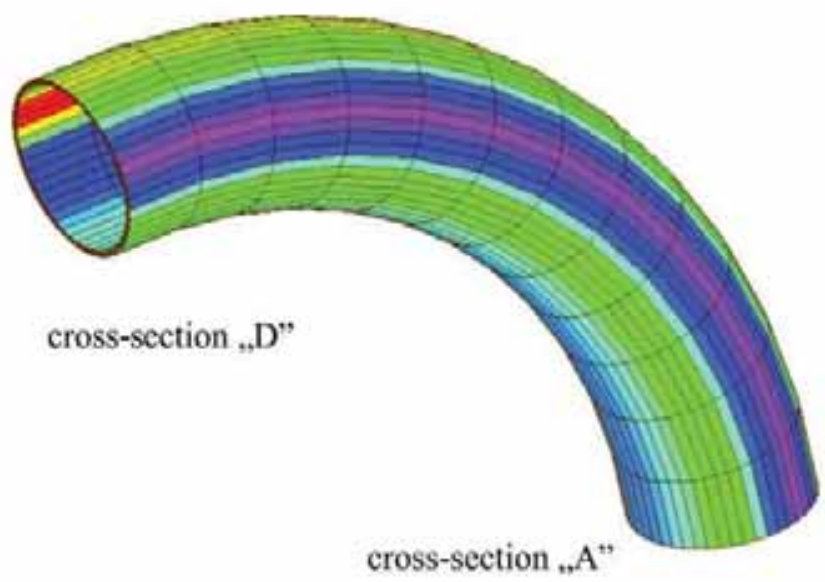

TANGENTIAL STRESS

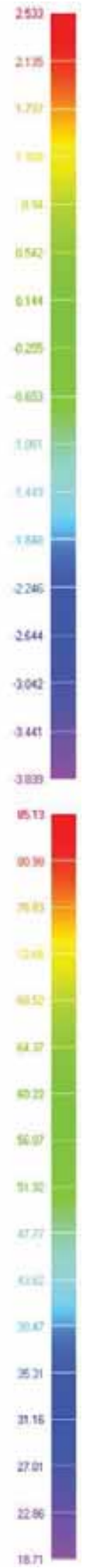

Figure 7: Radial and Tangential stresses 

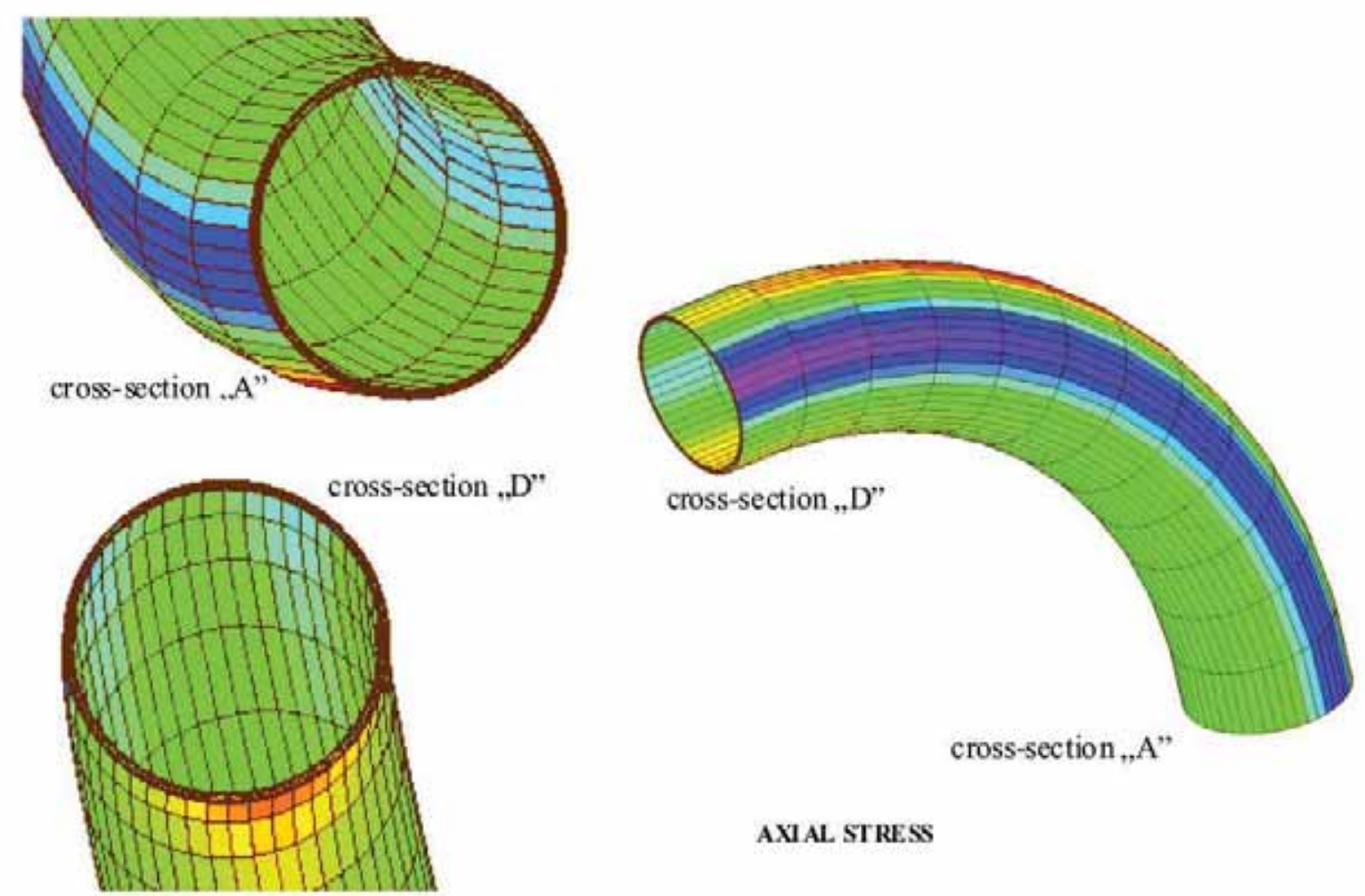

AXIAL STRESS

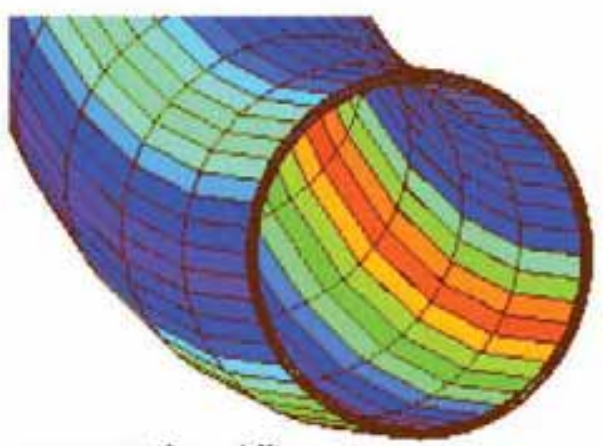

cross-section , $\mathrm{A}^{\prime \prime}$
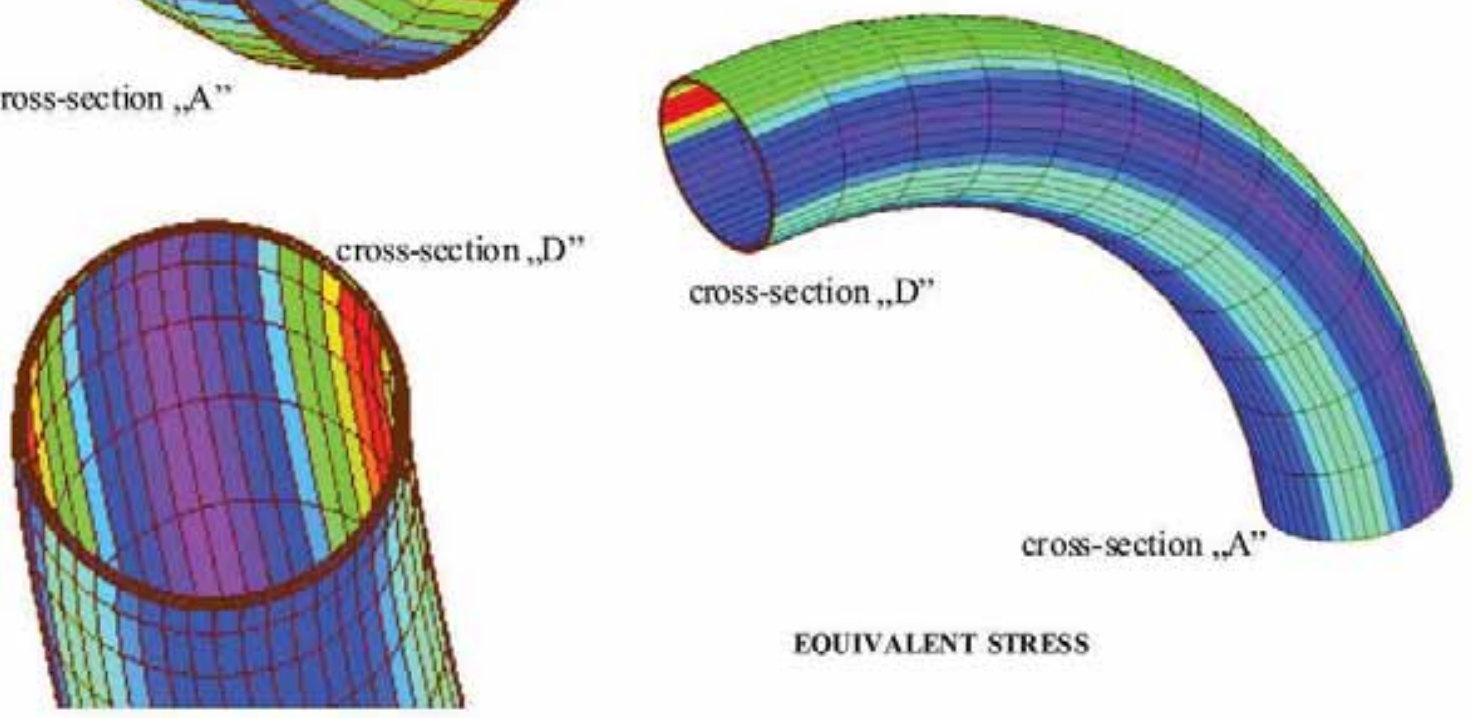

EOUIVALENT STRESS

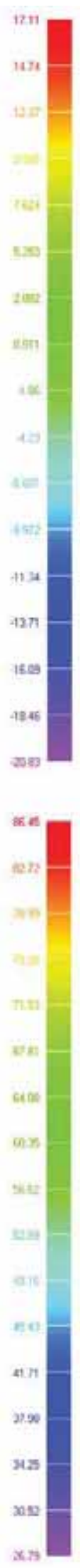

Figure 8: Axial and Equivalent stress 
Based on the presented results of stress distribution we can identify the presence of large local stresses (over $80 \mathrm{MPa}$ ), that exceed the standard material properties applicable to exploitation conditions, taking into account the fact that the steam lines have been exploited for more than 200,000 working hours [02]. Moreover, despite the influence of pipeline damage due to exploitation in the conditions of high temperature and pressure as well as of low cycle fatigue at the starting and stopping point of the facilities, the analysis of the model showed that such large stresses are the consequence of steam line support configuration [05].

\section{CONCLUSION}

The primary objective of this paper is to do stress analysis in order to estimate the reliability of the construction during the remaining lifecycle the using software packages based on the finite element theory. The paper presents the theoretical basis of beam superelement with $2 \mathrm{D}$ cross section segment, which PAK software is based on. Moreover, based on the obtained results it has been concluded that at the analyzed critical location there are local stresses that exceed the allowable standard value for the steam line which has already been exploited for more than 200,000 working hours. Further analysis of the model has led to the conclusion that so large stresses are the consequence of the steam line support configuration.

\section{ACKNOWLEDGEMENT}

The part of this research is supported by Ministry of Education, Science and Technological Development, Republic of Serbia, Grants TR32036 - Software development for solving coupled multiphysics problems.

\section{REFERENCES}

1) ALGOR PipePak, Pipe Stress Analysis and Design System for PC Workstations, ALGOR INC. (1993), Pittsburgh

2) American national standard "Power piping", Asme code for pressure piping, ASME/ANSI B31.1, (2001), American society of Mechanical Engineering, USA

3) Dr Maksimovi S., Blažić M, Maksimović, M. (2010): Design of constructions with respects to fatigue and fracture mechanics, Journal of Applied Engineering Science (Istraživanja i projektovanja za privredu), Vol. 8, No. 4, pp. 181-188

4) FEMAP User Guide, (2002), Unigraphic Solution Inc, Exton, USA

5) Jakovljevic A., (2004): Impact of damage and stress state of material to the remaining life cycle of high-pressure steam line (in Serbian), Beograd, master thesis

6) Kojic M., Slavkovic R., Zivkovic M., Grujovic N., (2003) User Manual for PAK-finite element program for linear and nonlinear structural analysis and heat transfer, Kragujevac, Faculty for Mechanical Engineering, University of Kragujevac

7) Kojic M., Slavkovic R., Živković M., Grujovic N., (1998): Finite element method I (in Serbian), Kragujevac, Faculty for Mechanical Engineering, University of Kragujevac

8) Pantelis N. Botsaris, E. I. Konstantinidis, D. Pitsa, (2012): Systemic assessment and analysis of factors affect the reliability of wind, Journal of Applied Engineering Science (Istraživanja i projektovanja za privredu), Vol. 10, No. 2, pp. 85-92

Paper sent to revision: 08.04.2013.

Paper ready for publication: 20.05.2013. 